\title{
Editorial
}

\section{Drug induced closure of patent ductus arteriosus}

\begin{abstract}
Patency of the arterial duct is maintained during gestation by locally produced and circulating prostaglandins. As gestation proceeds the duct becomes less sensitive to dilating prostaglandins and more sensitive to constricting influences, notably arterial oxygen tension.
\end{abstract}

\begin{abstract}
Closure of the fetal arterial duct
The arterial duct of the fetus is undoubtedly sensitive to prostaglandin synthetase inhibitors administered to the mother. These drugs may be taken by pregnant women for any of their standard uses and may specifically be prescribed to halt the progression of polyhydramnios, or to suppress labour. Persistent pulmonary hypertension in the newborn has been reported with fetal exposure to prostaglandin synthetase inhibitors ${ }^{12}$; however, this finding was not confirmed in larger series. ${ }^{3}$ Fetal duct closure and changes induced directly in the pulmonary vasculature by the drug are postulated in the genesis of pulmonary hypertension. ${ }^{3}$ Reversible constriction of the fetal duct during maternal indomethacin therapy is well described. ${ }^{4}$ It seems appropriate to recommend that the fetuses of mothers who are receiving this group of drugs should be assessed by serial echocardiography. This is particularly desirable when polyhydramnios is the clinical problem, as this may be associated with a number of congenital abnormalities which themselves are associated with an increased incidence of structural congenital heart disease in the fetus. Administration of a duct-constricting drug to a fetus with duct-dependent heart disease should ideally be avoided, but at the very least it should not be done in ignorance and its effects should be monitored carefully by ultrasound imaging and Doppler assessments.
\end{abstract}

\section{Postnatal ductal closure}

Delayed closure of the arterial duct in term infants, even those with severe respiratory problems, is uncommon and is probably a manifestation of structural congenital heart disease. In contrast, the situation which exists in the preterm is that a normal duct is deprived of normal stimuli or subject to abnormal ones and therefore remains open. In the case of a pre-term infant, there is a period when the ductus can be closed pharmacologically, earlier than spontaneous closure would otherwise occur. Term infants do not respond to duct-closing drugs. Detailed consideration of the indications for attempted pharmacological closure of the duct is outside the scope of this article 5 but they apply chiefly to infants with respiratory distress syndrome (RDS). Surfactant deficiency and lung immaturity causing respiratory failure are major causes of morbidity and mortality after pre-term birth. Ductal patency is associated with more severe acute respiratory illness, as well as a more prolonged course of respiratory disease in the extremely pre-term infant. The severity of RDS can be reduced by antenatal administration of dexamethasone, and one possible mechanism for this protective effect is steroid-mediated reduced ductal sensitivity to prostaglandin. ${ }^{6}$ There is only anecdotal evidence that postnatal steroid administration facilitates duct closure but, paradoxically, fetal exposure to indomethacin has been associated with a higher incidence of patent ductus arteriosus (PDA) as well as a poorer response of PDA to treatment. ${ }^{\text {? }}$

\section{Prophylactic drug administration}

Prophylactic administration of indomethacin within one or two days of birth does reduce the incidence of symptomatic patent ductus arteriosus (sPDA) ${ }^{8}$ but in one study a high relapse rate was described. ${ }^{9}$ Unfortunately, prediction of which infants are at risk from SPDA is not very sensitive and concerns about the safety of indomethacin mean that its prophylactic use cannot be advocated. Ethamsylate, a drug which inhibits production of many prostaglandins, has been shown to be associated with a reduced incidence of SPDA in a trial of its value in preventing periventricular haemorrhage in the pre-term newborn. ${ }^{10}$ Amato and colleagues ${ }^{11}$ subsequently showed in a small group of infants that parenteral ethamsylate given within four hours of birth and then every six hours for four days was associated with less SPDA $(2 / 10)$ than in controls $(8 / 10)$. This is too small a series to be able to recommend general use of ethamsylate to prevent sPDA.

\section{Therapeutic drug administration}

Diagnosis of sPDA is by a combination of clinical and, increasingly, echocardiographic means. When SPDA is detected, a short period of fluid restriction and diuretic administration may be tried, but if there is no rapid improvement, drug closure should be attempted. There is no doubt that indomethacin closes the duct in pre-term infants. In a national collaborative study of 3559 babies under $1750 \mathrm{~g}$ at birth $21 \%$ developed SPDA, and indomethacin resulted in closure of the duct within 48 hours of administration in $79 \%$ of the 135 infants given the drug, whereas in the same time scale, only $28 \%$ had closed spontaneously in the control group. ${ }^{12}$ Relapse occurred in $33 \%$ of responders, many of whom did not require further intervention. Overall, indomethacin had a success rate of $70 \%$. There have been a number of similar but smaller studies since and-though study details, patient populations, diagnostic criteria, and precise numbers differ-the basic message is that three doses of indomethacin (usually $0.2 \mathrm{mg} / \mathrm{kg}$ ) given intravenously to pre-term babies with sPDA over a period of 24 to 36 hours, results in closure of the ductus in about $70 \%$. Relapse has been looked at less closely but it is clear that some responders who relapse will require no further intervention and some will respond satisfactorily to a further three dose course. Gestation under 28 weeks and postnatal age beyond two weeks may be associated with a lower success rate. Indomethacin used in this way has a favourable effect on ventilatory requirement and nutrition, but there is 
little or no clear evidence that there is benefit in terms of survival, duration of hospital stay, or improved neurodevelopmental outcome.

These longer term outcomes are influenced by many factors and it seems reasonable to recommend closure of the ductus because of the short term benefits obtained. Continuing unanswered questions about the toxicity of indomethacin remain, however, and are of concern in view of the unclear long term benefits. Indomethacin interferes with platelet function and thrombocytopenia is generally considered a contraindication to its use. It is not clear how often this effect is clinically significant, and of greater importance is the potent vasoconstriction induced by indomethacin. Renal vasoconstriction results in oliguria, fluid retention, hyponatraemia, and increases in blood urea and creatinine concentrations. These effects are transient and rarely serious if fluid restriction is applied during treatment. Deteriorating or seriously impaired renal function is a contraindication to using the drug. Peripheral vasoconstriction during administration causes hypertension ${ }^{13}$ and derangement of intestinal arterial haemodynamics has been demonstrated by Doppler ultrasound. ${ }^{14}$ This latter effect may explain the gastrointestinal haemorrhage and perforation seen in under $10 \%$ of recipients of indomethacin. Cranial Doppler ultrasound demonstrates significant falls in cerebral blood flow velocity after rapidly administered indomethacin. ${ }^{13}$ If the drug is given over 30 minutes, ${ }^{15}$ cranial Doppler effects and cerebral electrical impedance changes are not seen. However, near infrared spectroscopy shows marked and prolonged reduction in cerebral blood flow and volume, cerebral oxygen delivery, and cerebral vascular responsiveness, regardless of the speed of administration of the drug. ${ }^{16}$ A prolonged (5 day) course of indomethacin ${ }^{17}$ has been shown to reduce the relapse rate and a prolonged (6 day) lower dose $(0 \cdot 1 \mathrm{mg} / \mathrm{kg} /$ day $)$ course $^{18}$ is associated with lower relapse rates and less biochemical disturbance. Unfortunately neither of these studies examined cerebral haemodynamics. The long term importance of these observations on disturbances in the cerebral circulation is unknown, as indomethacin has been shown to protect against periventricular haemorrhage ${ }^{8}$ which has a strong association with severe RDS and is a precursor of neurodevelopmental problems.

In the light of the above, it is of interest that a recent report ${ }^{19}$ demonstrated that ibuprofen closed the ductus in a small group of extremely pre-term infants as effectively as indomethacin but did not produce the cerebral effects shown on near infrared spectroscopy seen with indomethacin. This difference in effect on the cerebral circulation may be due to indomethacin acting on the cerebral vessels by means other than prostaglandin synthetase inhibition.

\section{Conclusion}

Safe and effective closure of sPDA in pre-term infants is still presenting a challenge. It is not even clear whether the cerebral effects of indomethacin are advantageous or deleterious. On evidence available to date, indomethacin treatment for sPDA in pre-term infants seems reasonable if a brief trial of fluid restriction and diuretics does not produce marked clinical improvement. More information is required on ibuprofen and other prostaglandin synthetase inhibitors such as mefenamic acid. Surgery has a high success rate and acceptable morbidity and should be employed if indomethacin fails to achieve duct closure or at least rapid clinical improvement or if contraindications to its use are present.

Departments of Paediatrics and Cardiology,

fohn Radcliffe Hospital, Oxford

1 Wilkinson AR, Aynsley-Green A, Mitchell MD. Persistent pulmonary hypertension and abnormal prostaglandin $\mathrm{E}$ levels in pre term infants
after maternal treatment with naproxen. Arch Dis Child 1979;54:942-5.

2 Manchester D, Margolis HS, Sheldon RE. Possible association between maternal indomethacin therapy and primary pulmonary hypertension in the newborn. Am f Obstet Gynecol 1976;126:467-9.

3 Moise KJ, Huhta JC, Sharif DS, Ou C-N, Kirshon B, Wasserstrum N, et al. Indomethacin in the treatment of pre term labour. $N$ Engl $\mathcal{f}$ Med 1988;319:327-31.

4 Eronen M, Pesonen E, Kurki T, Ylikorkala O, Hallman M. The effects of indomethacin and a $B$-sympatho-mimetic agent on the fetal ductus arteriosus during treatment of premature labor: a randomized double-blind riosus during treatment of premature labor:
study. Am $f$ Obstet Gynecol 1991;164:141-6.

5 Archer. N. Patent ductus arteriosus in the newborn. Arch Dis Child 1993;69: 529-32.

6 Clyman RI, Mauray F, Roman C, Rudolph AM, Heymann MA. Glucorticoids alter the sensitivity of the lamb ductus arteriosus to prostaglandin $\mathrm{E}_{2}$. $\mathcal{F}$ Pediatr 1981;98:126-8.

7 Norton ME, Merrill J, Cooper BA, Kuller JA, Clyman RI. Neonatal complications after administration of indomethacin for pre term labour. $N$ Engl f Med 1993;329:1602-7.

8 Ment LA, Oh W, Ehrenkranz RA, Philip AG, Vohr B, Allan W, et al. Low dose indomethacin and preventation of intraventricular haemorrhage: a multicenter randomized trial. Pediatrics 1994;93:543-50.

9 Cotton RB, Haywood JL, Fitzgerald GA. Symptomatic patent ductus arteriosus following prophylactic indomethacin. Biol Neonate 1991;60: 273-82.

10 Benson JW, Drayton MR, Hayward C. Multicentre trial of ethamsylate for prevention of periventricular haemorrhage in very low birth weight infants. Lancet 1986;ii:1297-1300.

11 Amato M, Huppi PS, Markus D. Prophylaxis of patent ductus arteriosus using ethamsylate in pre terms treated with exogenous surfactant. Acta Paediatr 1992;81:351-2.

12 Gersony WM, Peckham GJ, Ellison RC, Miettinen OS, Nadas AS. Effects of indomethacin in premature infants with patent ductus arteriousus: results of a national collaborative study. F Pediatr 1983;102:895-905.

13 Evans DH, Levene MI, Archer LNJ. The effect of indomethacin on cerebral blood flow velocity in premature infants. Dev Med Child Neurol 1987;29:776-82.

14 Coombs RC, Morgan MEI, Durbin GM, Both IW, McNeish AS. Gut blood flow velocities in the newborn: effects of patent ducuts arteriosus blood flow velocities in the newborn: effects of patent ducuts

15 Colditz P, Murphy D, Rolfe P, Wilkinson AR. Effect of infusion rate of indomethacin on cerebrovascular responses in pre term neonates. Arch Dis Child 1989;64:8-12.

16 Edwards AD, Wyatt JS, Richardson C, Potter A, Cope M, Delpy DT, et al. Effects of indomethacin on cerebral haemodynamics in very pre term infants. Lancet 1990;335:1491-5.

17 Hammerman C, Aramburo MJ. Prolonged indomethacin therapy for the prevention of recurrences of patent ductus arteriosus. $\mathcal{f}$ Pediatr 1990;117:771-6.

18 Rennie JM, Cooke RWI. Prolonged low dose indomethacin for persistent ductus arteriosus of prematurity. Arch Dis Child 1991;66:55-8.

19 Patel J, Marks KA, Roberts I, Azzopardi D, Edwards AD. Ibuprofen treatment of patent ductus arteriosus. Lancet 1995;346:255. 